\title{
RESIDUAL WEB BEARING CAPACITY OF CORRODED STEEL BEAMS
}

\author{
Yasser Sharifi \\ Department of Civil Engineering \\ Vali-e-Asr University of Rafsanjan, Rafsanjan, Iran \\ *(Corresponding author: E-mail:y.sharifi@vru.ac.irandyasser_sharifi@yahoo.com)
}

Received: 3 June 2011; Revised: 7 August 2011; Accepted: 11 August 2011

\begin{abstract}
Corrosion is one of the most pervasive types of structural problem experienced by steel girder structures especially in corrosive environments. Each of the damage modes, if not properly monitored and rectified, can potentially lead to catastrophic failure or unanticipated out-of-service time. The purpose of this paper is to propose a simple methodology to assess the residual strength capacity of steel girders under the degradations of corrosion. Two credible models have been developed for corrosion damaged steel I-beams based on the actual thickness loss data which come from the already literatures. Finally, to show the application of the proposed methodology, the residual web bearing capacity of corroded steel beams was estimated. It was found that it is possible to establish the applicable diagrams and flowchart which demonstrate the residual web bearing capacity assessment of steel I-beams as those ages.
\end{abstract}

Keywords: Corrosion, Steel structures, Web bearing capacity, Corrosion damaged models, Thickness loss data

\section{INTRODUCTION}

Corrosion is the major cause of deterioration in steel structures. Results of this deterioration can range from progressive weakening of the steel structure over a long period of time to sudden collapse of the structure. The effects of corrosion damage vary with the type of structure, the location and extent of deterioration. It has been pointed out by Kayser [1] the most important form of corrosion is general loss of surface material. General corrosion accounts for the largest percentage of corrosion damage. Corrosion damage must be carefully appraised and evaluated. In some cases, immediate repair or closure is necessary while in other cases, the conditions created by corrosion can be tolerated. In all cases, however, the likely progression of corrosion must be considered (Kulicki et al. [2]). While loss of material due to corrosion reduces the section properties and hence the carrying capacity of a member, it can also change the mode of failure from one to another depending on the rate and place of corrosion. The analysis of existing structures may differ from the analysis of structures under design, especially if there is damage by corrosion. Some of the assumptions made in design may no longer be true and other failure mechanisms may become significant (Sharifi and Rahgozar [3-8]).

Steel structures such as ships, offshore platforms and land-based structures are prone to suffer various types of damage as they get older. Corrosion and fatigue cracking may be the two most important types of damage in aging structures (Paik et al. [9,10]). Nakai et al. [11] studied that Corrosion is an unavoidable phenomenon in steel structures and thickness loss of the structural members due to corrosion is a great concern when the integrity of structures is considered. Concepts of 'corrosion margin' and 'allowable corrosion level' have been introduced conventionally to cope with this problem. The corrosion margin is an additional thickness at the design stage and the allowable corrosion level is used as a guide to determine when to renew worn members at the maintenance stage. It has been pointed out by Czarnecki and Nowak [12] corrosion can lead to cracking (fracture), yielding or bucking of members. This can result in stress concentration, changes in geometric parameters, and a build-up of the corrosion products. These parameters are critical for the member's ability to resist load effects. 
The effects of both uniform and pitting corrosion on load-carrying capacity and reliability of corrosion damaged steel box-girder bridges has been investigated by Sharifi and Paik [13,14] and Sharifi [15], respectively.

The effect of corrosion on structural strength is not yet clear. Further investigation is necessary to clarify how the corrosion affects strength of hold frames as beams. When beam strength is considered, (1) collapse strength (no buckling), (2) lateral-distortional buckling strength, (3) local buckling strength, (4) shear strength of web plates and (5) web crippling strength under concentrated loading etc. are important factors (Nethercot [16]).

It is possible to establish a relationship between the remaining capacities of various failure modes (moment, shear, lateral torsional buckling, bearing ...) and the loss of thickness for a given member. This approach can form the basis for establishing a quantitative relationship between the magnitude of corrosion defects and the corresponding remaining capacity. For a particular failure mode of a beam, if the percentage remaining capacity is plotted against the percentage loss of thickness, it will be obtained a curve that gives the relationship between them. The corrosion decay models, namely uniform and varying thickness loss models which are developed in this study will be used for the development of these curves. The results of this study can be used for a better prediction of the service life (remaining capacity) of deteriorating I-beams.

\section{MECHANISM OF STEEL CORROSION}

In order to produce steel, iron ores must be processed. During the process of metal extraction, it consumes a large amount of energy to separate the metal from the ore. Large amounts of energy are consumed in the manufacturing of metals. This energy is essentially stored in the metal. Because of the fact that all configurations in nature tend to spontaneously change to lower states of energy, refined metal will deteriorate or corrode. For steel structures, such as exposed to water, oxygen and salt, the rate of corrosion will be considerably increased by the presence of salt from a marine environment or the use of deicing materials. In the natural environment, it has a tendency to oxidise to a form similar to its natural state under the influence of air and water. This deterioration process is known as corrosion. In a more precise, it is an electro-chemical reaction in which water with various pollutants in solution acts as the electrolyte. Corrosion of steel is an electro-chemical process in which iron, Fe, reacts with oxygen to from iron oxides. The familiar iron compounds are: $\mathrm{Fe}(\mathrm{OH}) 2$, ferrous hydroxide; $\mathrm{Fe}(\mathrm{OH}) 3$, ferric hydroxide; Fe2O3, iron oxide; and Fe3O4, magnetite. When steel is attacked under humid conditions in a clean rural atmosphere, the first oxidation product is ferrous ion in the lowest oxidation state, namely, $\mathrm{Fe}+2$. because of the presence of air dissolved in moisture, the ferrous ion can react with it and precipitate ferrous hydroxide, $\mathrm{Fe}(\mathrm{OH}) 2$, which can be quickly oxidised further to the ferric state, $\mathrm{Fe}+3$, to give the gelatinous precipitate of ferric hydroxide (Fontana [17]).

\section{FORMS OF CORROSION}

There are five main forms of corrosion which can affect a steel girder. The most prevalent form is a general loss of surface material: this condition will lead to the gradual thinning of members. General corrosion accounts for the largest percentage of corrosion damage. Pitting corrosion also involves loss of material at the surface. However, it is restricted to a very small area. Galvanic corrosion occurs when two dissimilar metals are electrochemically coupled. Such situations may occur at bolted or welded connections. Galvanic corrosion can be local, leading to pit formation. Crevice corrosion occurs in small confined areas, such as beneath peeling paint or between faying 
surfaces. It is usually caused by a low concentration of dissolved oxygen in the moisture held within a crevice. Deep pits can also provide locations for crevice corrosion to occur. Stress corrosion occurs when metal is subjected to tensile stress in a corrosive environment (Fontana [17]).

\section{THE EFFECTS OF CORROSION ON STEEL STRUCTURES}

The effects of corrosion vary with the type of structure and the location and extent of deterioration. Steel structures can be affected by corrosion in many ways. The main effects can be loss of material from the surface, which leads to thinner sections. Section loss due to uniform corrosion may take place over a large area of a structural member. The loss of material due to uniform corrosion results in the reduction of section properties of a member, such as cross sectional area, moment of inertia, section modulus, radius of gyration and etc., thus causing a reduction in the carrying capacity of the structure. The stiffness of members may also be reduced due to loss of material which may cause excessive deflection. At severe levels of corrosion, the ultimate capacity of a steel member may fall below the service loads. Also it should be pointed out that the mode of failure due to loss of material can be changed due to fact that the class of section can be altered. For example, a plastic section may become semi-compact section due to loss of material and local buckling may prevent the development of full plastic moment (Sharifi and Rahgozar [3-8]).

\section{CORRODED SAMPLES OF STEEL}

Three identical universal mild steel I-beams $(305 \times 165$ UB40 kg) were recovered from the site where all in a severely corroded condition (nearly 40 years old) as shown in Figure 1 . The paint system had completely broken down with only remnants of the paint on the webs.

The thicknesses of these beams were measured by an instrument which was designed especially for this purpose. The instrument, which was used together with a depth gauge, is shown in Figure 2.

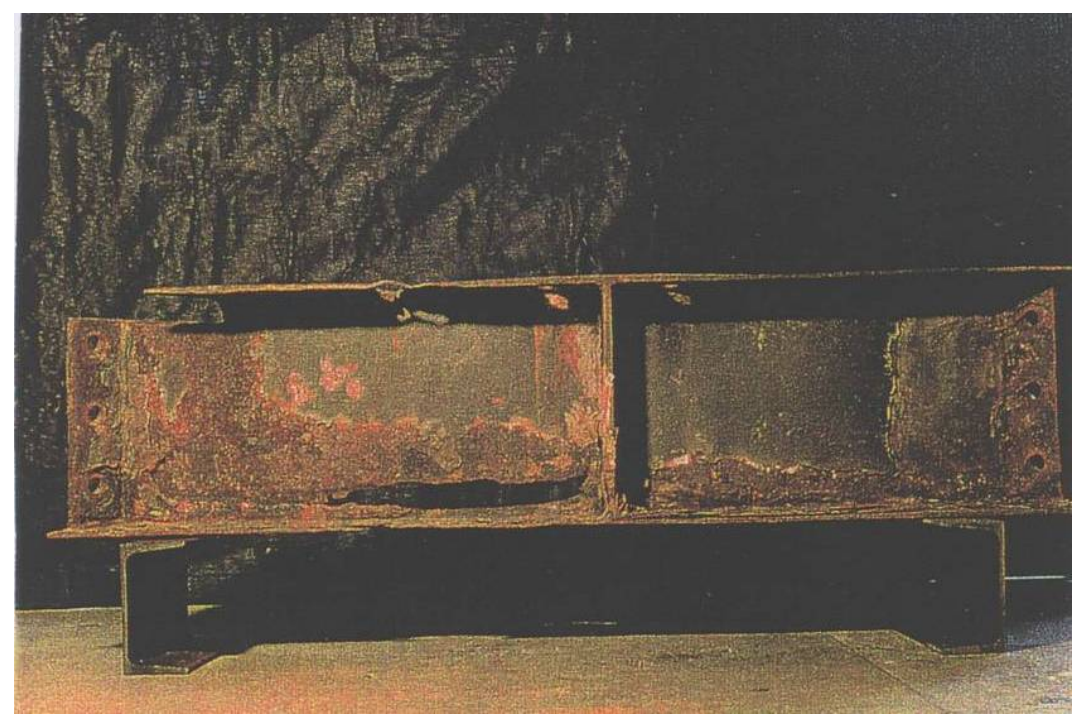

Figure 1. The Identical Corroded Universal Steel I-Beams 


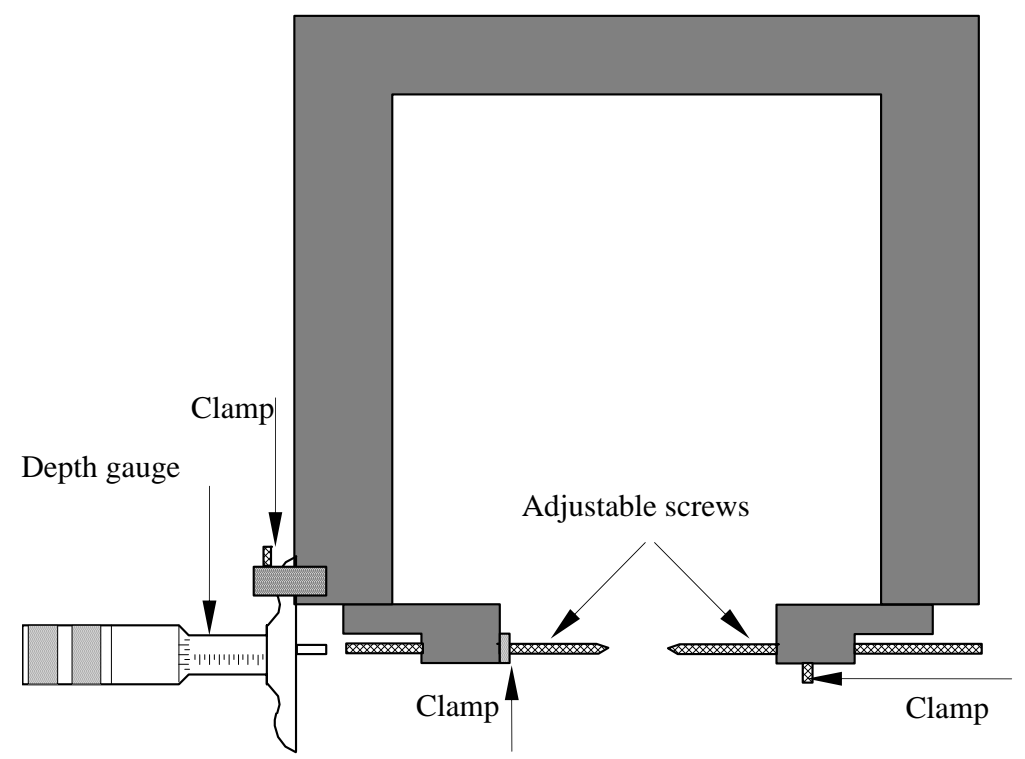

Figure 2. Instrument Used for Thickness Measurements of Sample Beams

As many readings as possible (up to 150 readings for each beam) were taken in order to increase the accuracy of the measurements. Average measurements of the thicknesses of each beam are shown in Table 1 . The loss of thickness on average was more significant in the flanges than in the webs.

Table 1. Average Measured Thicknesses of Corroded Beams (Rahgozar [18])

\begin{tabular}{lllll}
\hline \multirow{2}{*}{ Element } & As & Beam & Beam & Beam \\
& new & 1 & 2 & 3 \\
\hline Average thickness of top flange & 10.20 & 7.45 & 7.81 & 7.23 \\
\hline Average thickness of bottom flange & 10.20 & 5.62 & 5.85 & 4.84 \\
\hline Average thickness of top and bottom flanges & 10.20 & 6.54 & 6.83 & 6.04 \\
\hline Average thickness loss of top and bottom flanges & 0.00 & 3.66 & 3.37 & 4.16 \\
\hline $\begin{array}{l}\text { Percentage average thickness loss of top and } \\
\text { bottom flanges }\end{array}$ & 0.00 & $35.9 \%$ & \multirow{2}{*}{$33.3 \%$} & \multirow{2}{*}{$40.8 \%$} \\
\hline Average thickness of upper part of web $\left(0.75 \mathrm{~h}_{\mathrm{w}}\right)$ & 6.10 & 5.63 & 5.74 & 5.45 \\
\hline Average thickness of lower part of web $\left(0.25 \mathrm{~h}_{\mathrm{w}}\right)$ & 6.10 & 3.16 & 4.32 & 3.18 \\
\hline Average thickness of web & 6.10 & 5.01 & 5.39 & 4.88 \\
\hline Average thickness loss of web (mm) & 0.00 & 1.09 & 0.71 & 1.22 \\
\hline Percentage average thickness loss of web & 0.00 & $17.8 \%$ & $11.7 \%$ & $20.0 \%$ \\
\hline
\end{tabular}

Note: $\mathrm{h}_{\mathrm{w}}=$ depth of web, all measurements are in millimeters

\section{ANALYSIS OF THE EFFECT OF CORROSION DAMAGE OF STEEL BEAMS}

\subsection{Corrosion Decay Models}

Corrosion of steel occurs when the electrolytes are present on the surface, particularly in places where water and contaminants can accumulate. The places most commonly found with corrosion are the top surface of the bottom flange where water collects from dew or splash and on the web near the abutments and joints. It has been pointed out by Kayser and Nowak [19] that severe corrosion may take place at the bottom one quarter of the web. Therefore the top surface of the bottom flange and the bottom part of the web are the regions where severe corrosion may take place, as shown in Figures 3. Corrosion also takes place in the top flange and the top part of the web but the loss is much less as compared to that of the web's bottom part. 


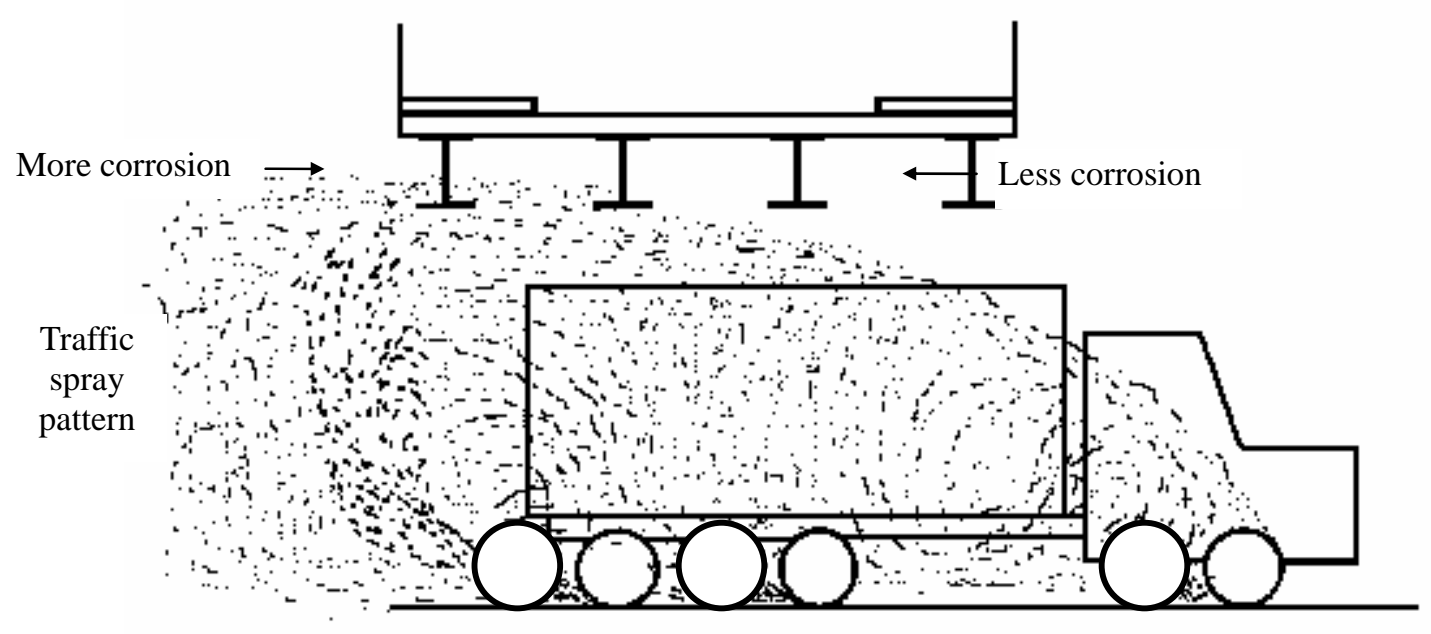

Figure 3(a) The Traffic Spray Accumulation on Girder Flanges and Webs

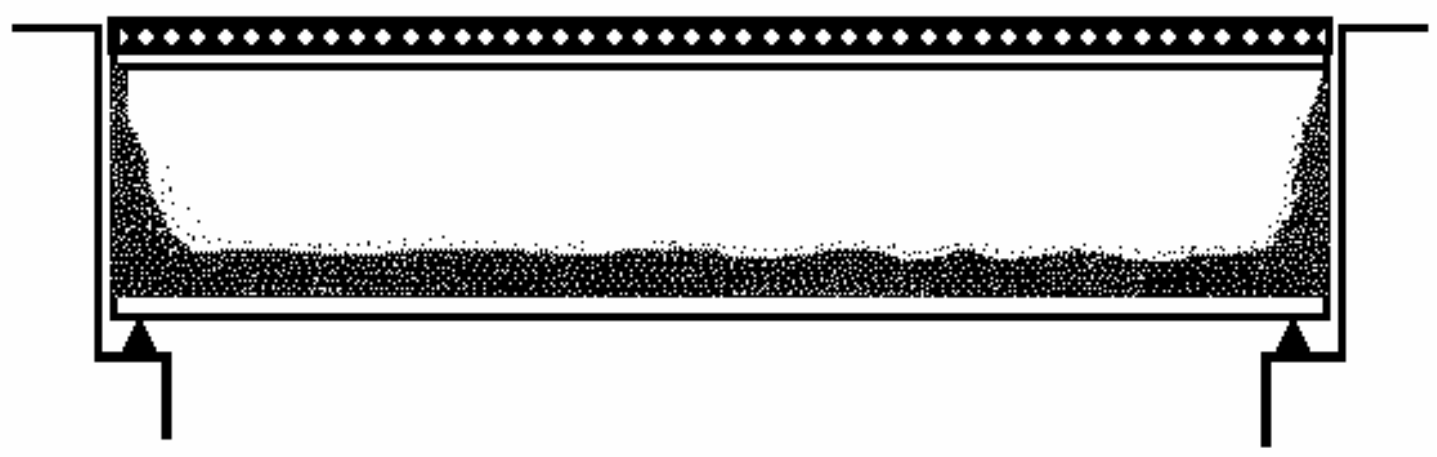

Figure 3(b). Typical Locations where Corrosion can occur on a Steel Girder Bridge

The development of corrosion decay models mainly requires the information on the locations where corrosion normally occurs and the types of corrosion damage of steel members. The most common form of corrosion damage of steel is general surface corrosion. The locations where corrosion occurs were discussed earlier. From these discussions, basic conclusions were made concerning the location of corrosion. Using this information, two corrosion decay models were considered by reducing the thickness of the sections. The two models which are shown in Figures 4 are as follow: 


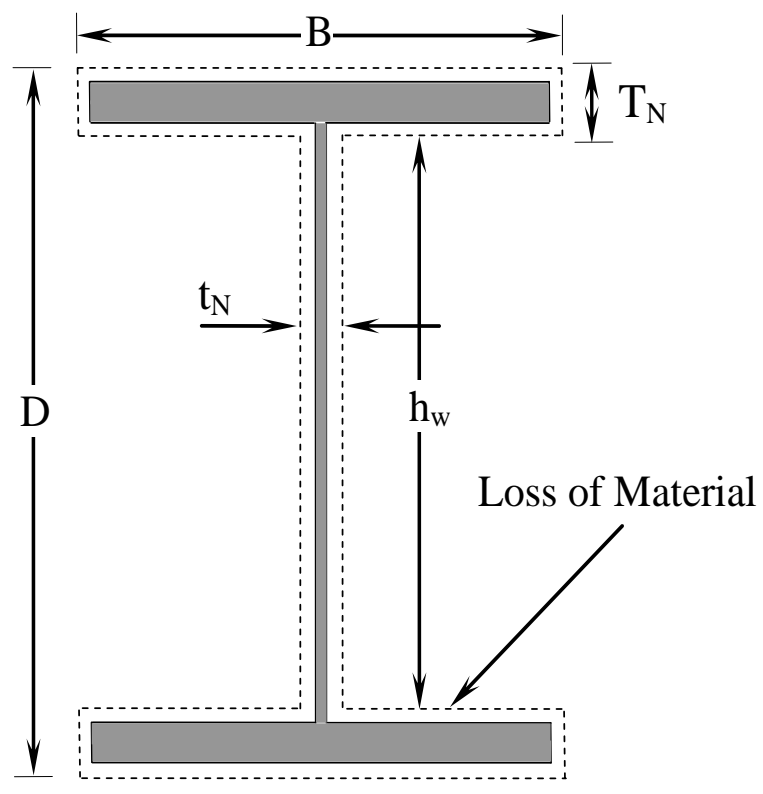

\section{Loss of Material}

Flanges $\quad \mu T_{N}$

Web $\quad \mu t_{N}$

Where $T_{N}$ and $t_{N}$ are the thicknesses of the flanges and web of as-new section, $\mu=\% L F T / 100=\% L W T / 100, \mu=\mu_{F}=\mu_{W}$ $\% L F T=$ Percentage loss of flange thickness $\% L W T=$ Percentage loss of web thickness

Figure 4(a). Uniform Thickness Loss in both Flanges and Web (Model 1)

Thickness of the top flange $=T_{N}(1-\mu)$

Thickness of the bottom flange $=T_{N}(1-\mu)$

Average thickness of the flanges, $T_{C}=T_{N}(1-\mu)$

Thickness of the web, $t_{c}=t_{N}(1-\mu)$

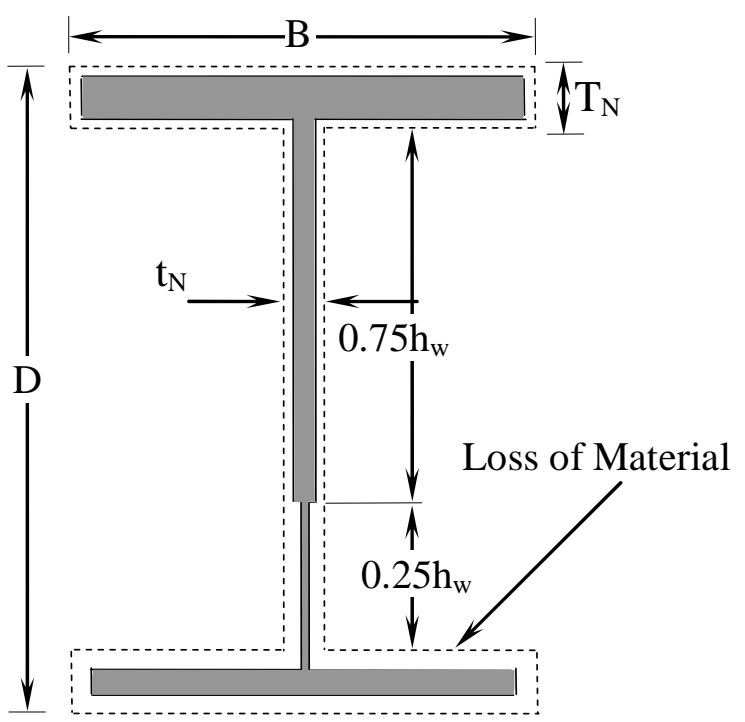

\section{Loss of Material}

Top flange

$0.7 \mu T_{N}$

Upper part of the web

$\left(0.75 h_{w}\right)$

$0.25 \mu t_{N}$

Lower part of the web

$\left(0.25 h_{w}\right)$

$1.25 \mu t_{N}$

Bottom flange

$1.3 \mu T_{N}$

where $\mu=\% L F T / 100$

Figure 4(b). Varying Thickness Loss in both Flanges and Web (Model 2)

Figure 4. Corrosion Decay Models Simulated By Reducing the Thickness of Elements

Thickness of the top flange $=T_{N}(1-0.7 \mu)$

Thickness of the bottom flange $=T_{N}(1-1.3 \mu)$

Average thickness of the flanges $T_{c}=T_{N}(1-\mu)$

Thickness of the upper part of the web $\left(0.75 h_{w}\right)=t_{N}(1-0.25 \mu)$

Thickness of the lower part of the web $\left(0.25 h_{w}\right)=t_{N}(1-1.25 \mu)$

Average thickness of the web, $t_{c}=t_{N}(1-0.5 \mu)$

Where $\mu=\mu_{F}=2 \mu_{W}$. 
In the case of model 2, the thickness loss of flanges and web were in similar proportion to the thickness loss of the samples of corrosion damaged beams obtained from a chemical plant (Table 1). The measured thicknesses of these beams are given in Table 1. It can be established from Table 1 that the thickness loss of the bottom flange of sample beams is approximately twice as that of the loss of the top flange. The thickness loss of the lower part of the web $(0.25 \mathrm{hw})$ is nearly five times as that of the upper part of the web $(0.75 \mathrm{hw})$. For two sample beams the average thickness loss of the web is approximately half of that of the average loss of the flanges. These ratios were used for the development of Model 2 (varying thickness loss model) as shown in Figure 4(b).

The thickness loss of the stiffeners of all the sample beams is very minimal, i.e. only about $10 \%$ of its original thickness. It is also observed that the percentage thickness loss of the stiffeners is nearly the same as that of the upper part of the web. Therefore, for the corrosion decay models, it was assumed that the loss of material in the stiffeners was in similar proportion to the thickness loss of the upper part of the web.

\section{WEB BEARING CAPACITY}

Plate elements (e.g. webs) are subjected to bearing stresses by concentrated loads or locally distributed edge loads (reactions from supports or other members) as shown in Figure 5. For example, a concentrated load applied to the top flange of a beam induces local bearing stresses in the web immediately beneath the load. When the load reaches its critical value, the web crushes (cripples) by combined compression and folding directly under the load.

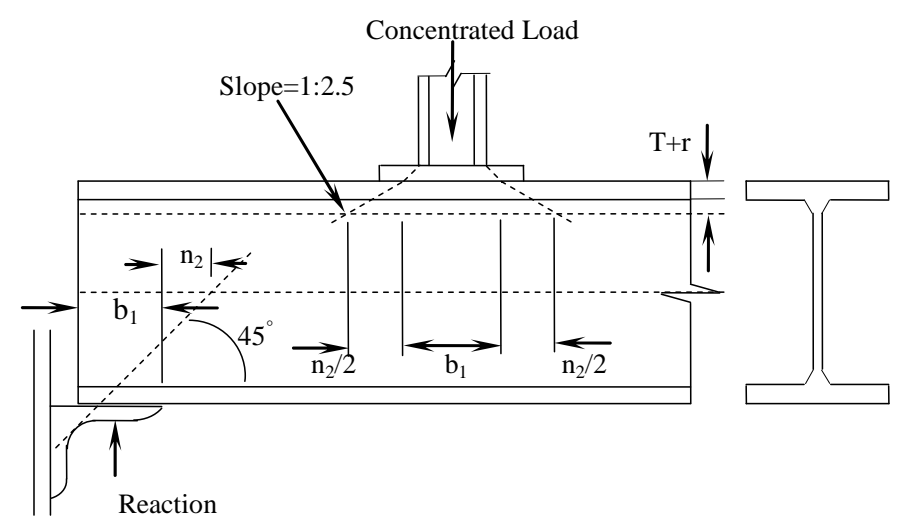

Figure 5. Effective Web Bearing Length to Resist Crushing

The ultimate bearing strength of a thick web depends on its design strength, $p_{y}$. although yielding first occurs under the centre of the bearing plate, general yielding does not takes place until the applied load is large enough to cases yielding of a web area defined by a dispersion of the applied load is large enough the flange. Even at this load the web does not collapse catastrophically, and some further yielding and redistribution is possible (Trahair et al. [20]).

Where point loads or reactions from supports or other members are applied to a beam as shown in Figure 5 then the web should be checked for bearing stresses. The web bearing strength, $P_{w b}$, is given by

$P_{w b}=\left(b_{1}+n_{2}\right) t p_{y}$

where 
$b_{1}$ is the stiff bearing length,

$n_{2}$ is the length obtained by the slope 1:2.5 dispersion through the flange and can be taken as follows :

$n_{2}=2 \times 2.5(T+r)$ for forces applied through a flange by loads or reactions in the length between the ends and

$n_{2}=2.5(T+r)$ for forces applied through a flange by loads or reactions at the ends,

$t$ is the thickness of the web and,

$p_{y}$ is the design strength of the web.

The code recommends that if the force applied through a flange by loads or reactions exceeds the local capacity of the web at its connection to the flange, then bearing stiffeners should be provided.

\section{ASSESSMENT METHODS FOR EVALUATION THE RESIDUAL WEB BEARING CAPACITY}

\subsection{Simple Assessment Method Using the Developed Corrosion Decay Models}

The web bearing strength, $P_{w b}$, of a section can be evaluated using the theory given in Section 7, in which the web bearing strength is given as follows:

$P_{w b}=\left(b_{1}+n_{2}\right) t p_{y}$

Equation 4 may be written as:

$P_{w b g}=\left[b_{1}+2.5 c(T+r)\right] t p_{y}$

where

$c=2$ for forces applied through a flange by loads or reactions in the length between the ends, and

$c=1$ for forces applied through a flange by loads or reactions at the ends.

The percentage residual web bearing capacity $(\% R W B C)$ of a corrosion damaged section can be presented the capacity of corrosion section $\left(W B C_{C}\right)$ to the capacity of the section in its new condition $\left(W B C_{N}\right)$. It can be expressed as:

$\% R W B C=100\left(W B C_{C} / W B C_{N}\right)$

Using Equation 5, the $\% R W B C$ is obtained as:

$\% R W B C=100 \frac{t_{C}}{t_{N}} \frac{\left[b_{1}+2.5 c\left(T_{C}+r\right)\right]}{\left[b_{1}+2.5 c\left(T_{N}+r\right)\right]}$

The root radius, $r$, may be taken as constant throughout the service life of a beam. Equation 7 shows that the design strength has no effects on the $\% R W B C$. In order to obtain a minimum for the $\% R W B C$, it is necessary to identify the worst possible case, which can be taken as when $b_{1}=0$, i.e. stiff bearing plates are not provided. Substituting $b_{1}=0$ into Equation 7 gives the $\% R W B C$ as:

$\% R W B C=100 \frac{t_{C}}{t_{N}}\left(\frac{T_{C}+r}{T_{N}+r}\right)$

For uniform thickness loss model sections in which $\mu=\mu_{F}=\mu_{W}$ where $\mu=\% L F T / 100$, if Equations 
1a and $1 \mathrm{~b}$ (for $T_{C}$ and $t_{c}$ ) are combined with Equation 8, the following relation is obtained for the $\% R W B C$ as:

$\% R W B C=100(1-\mu) \frac{(1-\mu)+\left(r / T_{N}\right)}{1+\left(r / T_{N}\right)}$

Equation 9 shows that when $\left(r / T_{N}\right)$ decreases, the $\% R W B C$ also decreases. Hence, the minimum of $\% R W B C$ can be obtained when the value of $\left(r / T_{N}\right)$ is the minimum. By analysing the available I-sections for UK steel manufactured, the minimum of $\left(r / T_{N}\right)$ was obtained as 0.5 for section $U B 29$ (457×191 UB 98). Now, substituting the minimum of $\left(r / T_{N}\right)$ into Equation 9 gives the minimum of $\% R W B C$ of uniform thickness loss model sections as:

$\operatorname{Min}(\% R W B C)=100(1-\mu)\left(1-\frac{2}{3} \mu\right)$

For varying thickness loss model sections in which $\mu=\mu_{F}=2 \mu_{W}$, combining Equation 2c, 2f (for $T_{C}$ and $\left.t_{C}\right)$ and 8 together with the minimum value of $\left(r / T_{N}\right)$ gives the minimum of $\% R W B C$ as:

$\operatorname{Min}(\% R W B C)=100(1-\mu)\left(1-\frac{4}{3} \mu\right)$

Therefore, Equations 10 and 11 may be used as the minimum curves for estimating the percentage remaining web bearing capacity of corrosion damaged beams that are not provided with web bearing stiffeners. The evaluated equations $(10,11)$ have been shown in Figure 6 for uniform and varying corrosion decay models. These two equations, which are derived from the developed corrosion models, are named as simple.

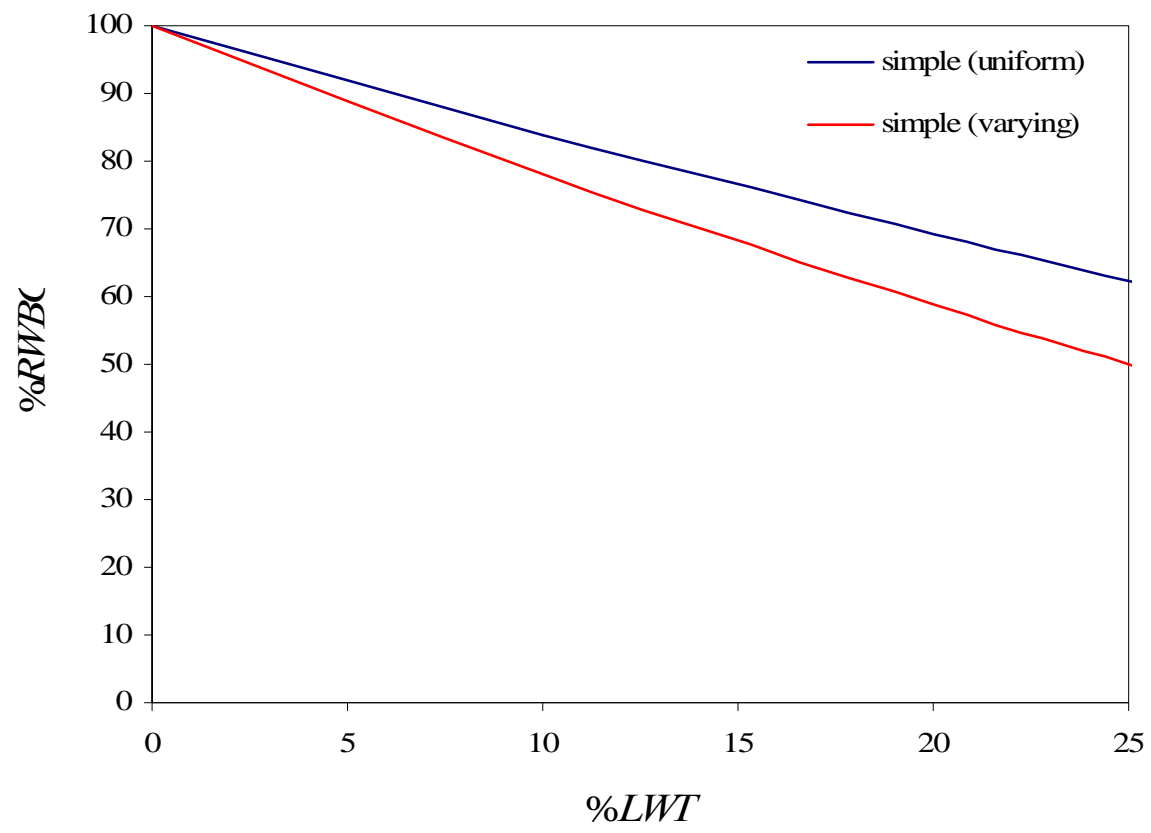

Figure 6. Minimum Curves of Simple Assessment Methods for Uniform and Varying Corrosion Models 


\subsection{Accurate Assessment Method}

Here, it has been decided to employ this procedure for UK steel manufactured I-sections. The accurate assessment method involves analyzing all the I-sections (71 sections) manufactured in the UK. This will require a considerable amount of man hours and computer time to identify the section that gives the minimum curve. The aforementioned problem was minimized by using the following procedure that involves only about 25 sections and a computer programming. First, a family of sections (i.e. sections, which have the same serial size) was analyzed to observe their behavior regarding a particular failure mode and to identify the section that gives the minimum curve for the family. Considering the above observation, the sections with similar properties from each of the families were analyzed to identify the section that gives the minimum curve for all the sections. For simplicity, the results of the analysis are given in this study for only a few sections including the sections that have the maximum and minimum percentage residual capacity. The sections are numbered according to their position in the section table (e.g. $U B 1, U B 2$, etc.).

A family of sections with varying thickness loss was analyzed to study the behaviour of $\% R W B C$ of corrosion damaged sections that are not provided with web bearing stiffeners. The results and the detail of the family of sections are given in Figure 7.

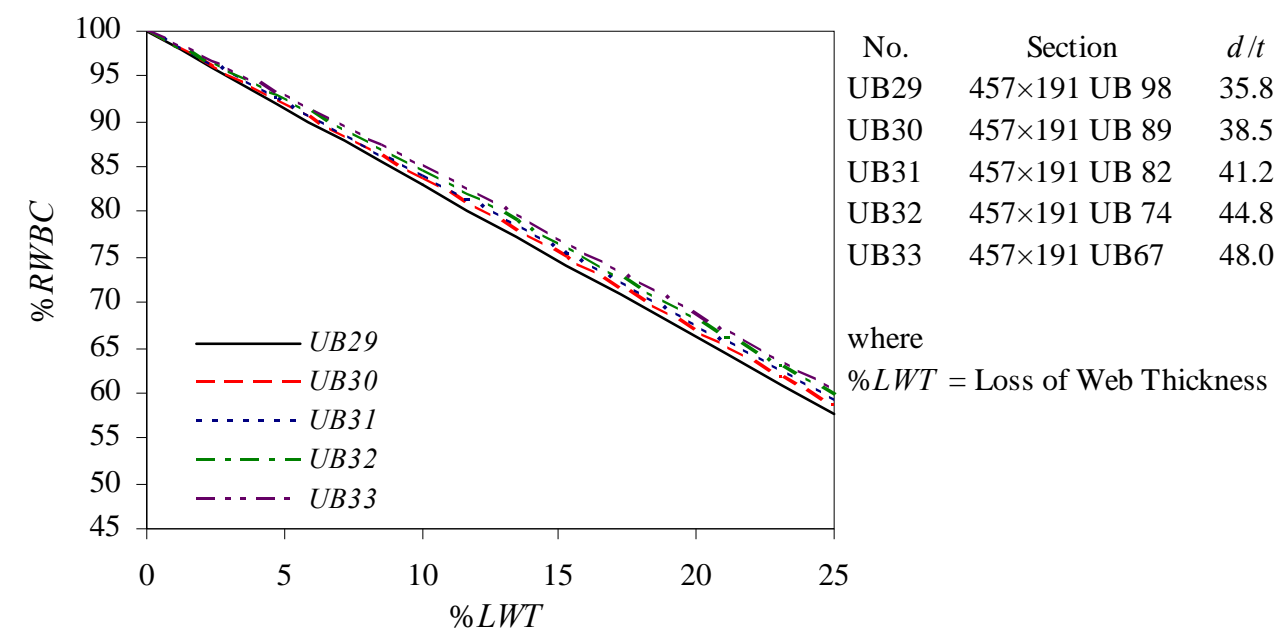

Figure 7. Behavior of $\% R W B C$ of a Family of Sections

It can be seen from Figure 7 that the section with the lowest value of $d / t$ (UB29) gives the minimum curve for the $\% R W B C$ of the family of sections. Based on the above observation, sections that have the lowest value of $d / t$ from each of the families were analyzed to obtain a minimum curve for the $\% R W B C$. The results for five beams and the details of the sections are given in Figure 8. 


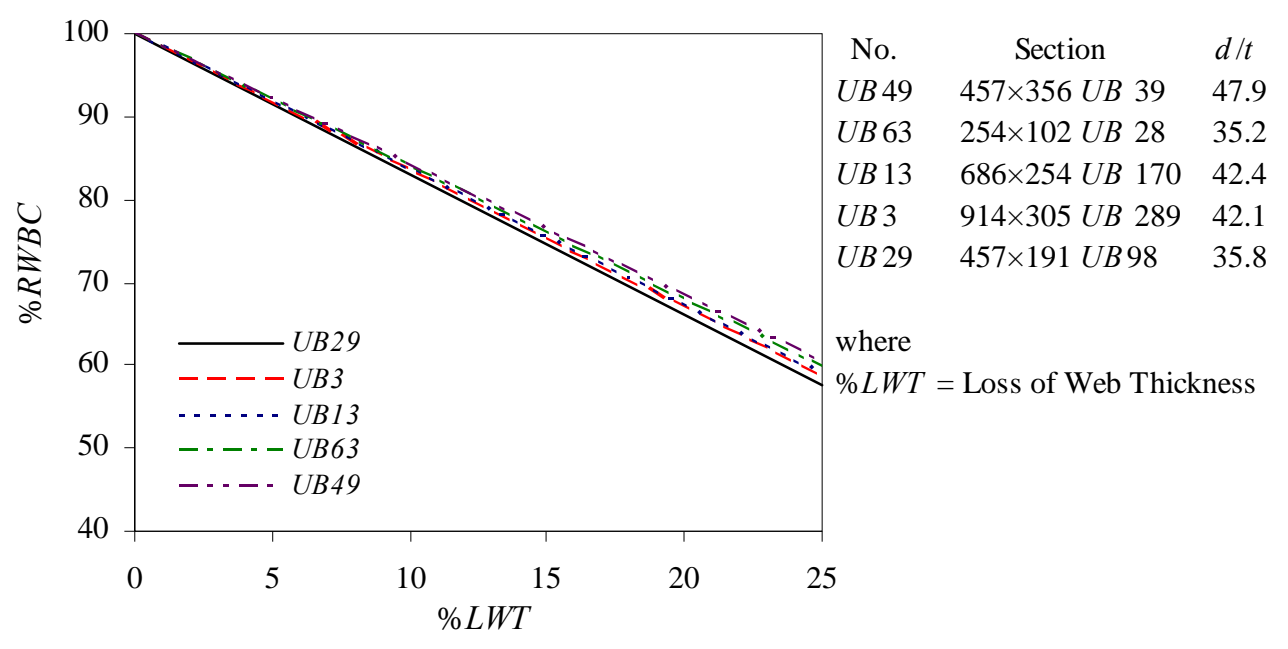

Figure 8. Behavior of \% RWBC of Sections from Five Families

It is evident from Figure 8 that the section that has the lowest value of $d / t$ ratio (UB29) gives the minimum curve for the \% $R W B C$ of the whole range of corrosion damaged beams that are not provided with web bearing stiffeners. The variation in the percentage remaining capacities between the maximum and minimum values of $d / t$ ratio is small (less than $7 \%$ for web thickness loss of $25 \%)$.

\section{MINIMUM CURVES}

It was found in the analysis that the section with the lowest value of $d / t$ (UB29) gives the minimum curve for the \% $R W B C$ of corrosion damaged sections that are not provided with web bearing stiffeners. The results of simple assessment have been compared with the minimum curves which are concluded from the accurate procedure in Figure 9 for uniform and varying thickness loss models.

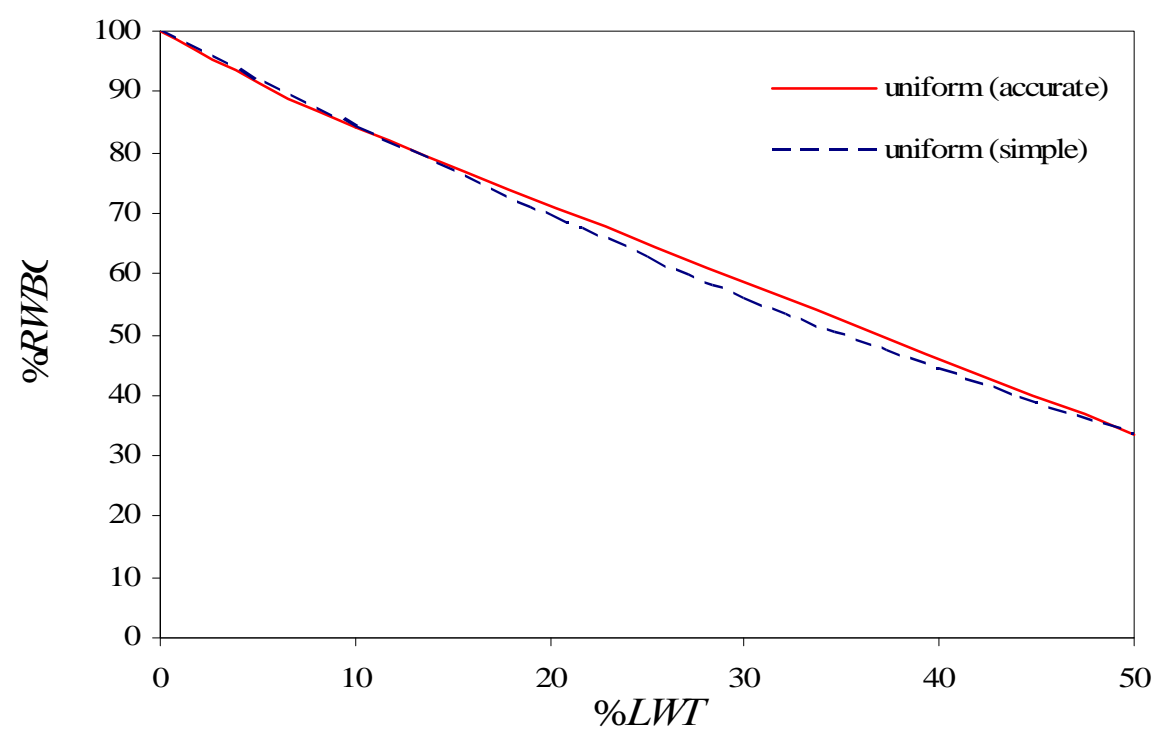

Figure 9(a). Minimum Curve to Estimate the \%RWBC of Corroded Steel I-Beam Due to Uniform Corrosion Models 


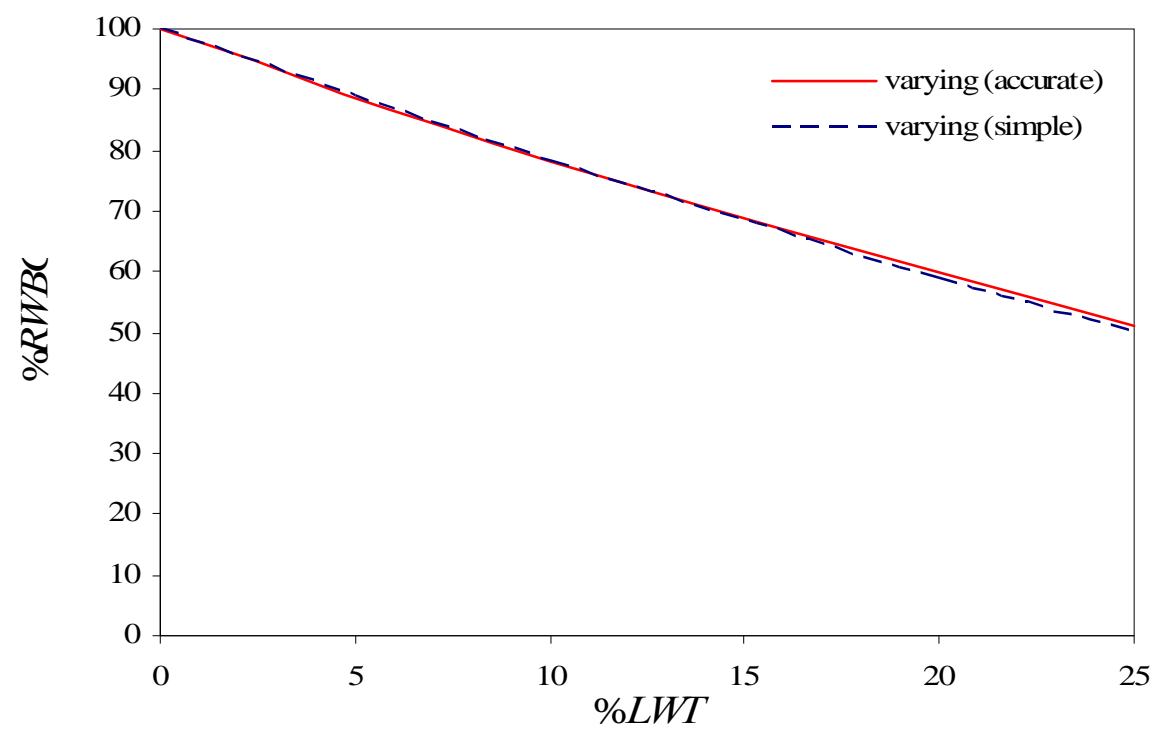

Figure 9(b). Minimum Curve to Estimate the \%RWBC of Corroded Steel I-Beam Due to Varying Corrosion Models

From Figures 9 it is evident that the proposed simple method has a good agreement with the real load-carrying capacity (accurate method). Therefore, this procedure can be used to estimate the load-carrying capacity of corroded steel I-beams. Therefore, this procedure has been schematically shown in Figure 10. A practice engineer can evaluate the remaining web bearing capacity by using this flowchart.

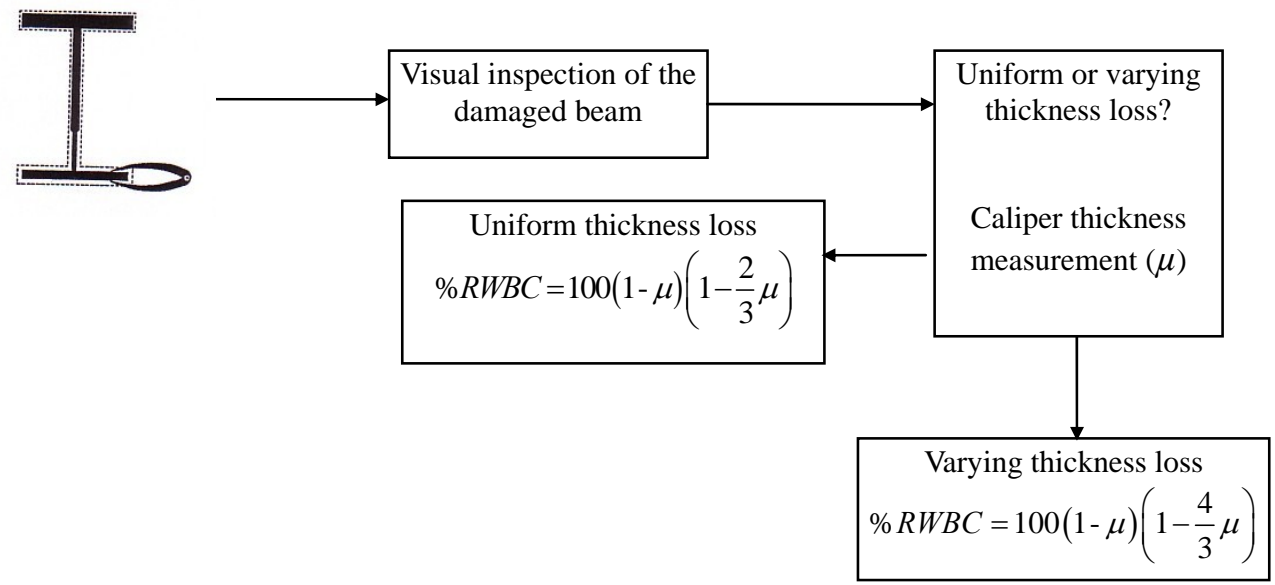

Figure 10. Procedures for Predicting the Remaining Web Bearing Capacity of a Corroded Steel Beam

\section{CONCLUSIONS}

It was shown by the accurate assessment method that, it is possible to obtain minimum curves that can be used to estimate the load-carrying capacities of corrosion damaged beams with considerable accuracy. Two credible corrosion models for steel I-beams sections have been developed based on the real corrosion loss data. By taking into account the effect of corrosion on the strength capacities (e.g., moment, shear, web bearing, ...) the minimum curves can be obtained. Here, the foregoing approach was employed in order to derive the residual web bearing capacity of corroded steel beams. Since there is a good agreement between the proposed (simple) and accurate assessment methods, the 
validity of proposed analytical method (simple assessment method) is confirmed and these formulae may be used with the information on the loss of thicknesses of the section to estimate the percentage residual web bearing of corroded sections. The results of this research will help the practicing engineer to make a fast and reliable decision regarding the residual strength capacities of corrosion damaged I-beam.

\section{ACKNOWLEDGEMENT}

The author is pleased to acknowledge the Vali-e-Asr University of Rafsanjan support.

\section{REFERENCES}

[1] Kayser, J. R., “The Effects of Corrosion on The Reliability of Steel Girder Bridges”, PhD thesis, Department of Civil Engineering, University of Michigan, 1988.

[2] Kulicki, J.M., Prucs, Z., Sorgenfrei, D.F. and Mertz, D.R., "Guidelines for Evaluating Corrosion Effects in Existing Steel Bridges”, National Cooperative Highway Research Program, Report 333, Transportation Research Board, National Research Council, Washington, D.C; 1990.

[3] Sharifi, Y. and Rahgozar, R., "Evaluation of the Remaining Shear Capacity in Corroded Steel I-Beams”, International Journal of advanced Steel Construction, 2010, Vol. 6, No. 2, pp. 803-816.

[4] Sharifi, Y. and Rahgozar, R., "Remaining Moment Capacity of Corroded Steel Beams", International Journal of Steel Structures, 2010, Vol. 10, No. 2, pp. 165-176.

[5] Sharifi Y. and Rahgozar R., "Simple Assessment Method to Estimate the Remaining Moment Capacity of Corroded I-Beam Sections”, Scientia Iranica Journal, 2010, Vol. 17, No. 2, pp. 161-167.

[6] Sharifi Y. and Rahgozar R., "Evaluation of the Remaining Lateral Torsional Buckling Capacity in Corroded Steel Beams”, Journal of Zhejiang University SCIENCE A, 2010, Vol. 11, No. 11, pp. 887-897.

[7] Rahgozar R., Sharifi, Y. and Malekinejad, M., "Buckling Capacity of Uniformly Corroded Steel Members in terms of Exposure Time”, Steel and Composite Structures, 2010, Vol. 10, No. 6, pp. 475-487.

[8] Sharifi, Y. and Rahgozar, R., "Fatigue Notch Factor in Steel Bridges Due to Corrosion", Archives of Civil and Mechanical Engineering, 2009, Vol. IX, No. 4, pp. 75-83.

[9] Paik, J.K., Lee, J.M. and Ko, M.J., "Ultimate Compressive Strength of Plate Elements with Pit Corrosion Wastage”, Journal of Engineering Maritime Environnent, 2003, Vol. 217, No. M4, pp. 185-200.

[10] Paik, J.K., Lee, J.M. and Ko, M.J., "Ultimate Shear Strength of Plate Elements with Pit Corrosion Wastage”, Thin-Walled Structures, 2004, Vol. 42, No. 8, pp. 1161-76.

[11] Nakai, T., Matsushita, H. and Yamamoto, N., "Effect of Pitting Corrosion on the Ultimate Strength of Steel Plates Subjected to In-Plane Compression and Bending”. Journal of Marine Science and Technology, 2006, Vol. 11, No. 1, pp. 52-64.

[12] Czarnecki, A.A. and Nowak, A.S., "Time-Variant Reliability Profiles for Steel Girder Bridges”, Structural Safety, 2008, Vol. 30, No. 49-64.

[13] Sharifi, Y. and Paik, J.K., "Ultimate Strength Reliability Analysis of Corroded Steel-box Girder Bridges”, Thin-Walled Structures, 2011, Vol. 49, No. 1, pp. 157-166.

[14] Sharifi, Y. and Paik, J.K., "Environmental Effects on Ultimate Strength Reliability of Corroded Steel Box Girder Bridges”, Structural Longevity, 2010, Vol. 18, No. 1, pp. 1-20. 
[15] Sharifi, Y. "Reliability of Deteriorating Steel Box-Girder Bridges under Pitting Corrosion”, International Journal of advanced Steel Construction, 2011, Vol. 7, No. 3, pp. 220-238.

[16] Nethercot, D. A., "Limit States Design of Structural Steelwork", 3rd ed. Spon Press, London, UK, 2001.

[17] Fontana, M. G., “Corrosion Engineering”, McGraw Hill Book Company, New York, Third Edition, 1987.

[18] Rahgozar, R., "Remaining Capacity Assessment of Corrosion Damaged Beams using Minimum Curves”, Journal of Constructional Steel Research, 2009, Vol. 65, pp. 299-307.

[19] Kayser, J. R. and Nowak, A. S., "Capacity Loss Due to Corrosion in Steel-Girder Bridges”, Journal of Structural Engineering, ASCE, 1989, 115, pp. 1525-1537.

[20] Trahair, N. S., Bradford, M. A. and Nethercot D. A, "The Behavior and Design of Steel Structures to BS5950”, Third Edition-British, London, Spon Press, Taylor \& Francis Group, 2001. 